\title{
Perancangan Sistem Peringatan Antar Kendaraan Untuk Peningkatan Keselamatan Berkendara di Jalan
}

\author{
Ibrahim Abduh ${ }^{1)}$, Dahlia Nur ${ }^{2)}$, Muh. Ahyar ${ }^{3)}$, Hafsah Nirwana ${ }^{4)}$ \\ Jurusan Teknik Elektro Politeknik Negeri Ujung Pandang \\ ${ }^{1}$ ibrahimabduh@poliupg.ac.id \\ 2dahlia@poliupg.ac.id \\ 3 ahyar@poliupg.ac.id \\ 4yayeng555@yahoo.co.id
}

\begin{abstract}
Abstract- Banyaknya kejadian kecelakaan lalu lintas di Indonesia yang menunjukkan kondisi keselamatan jalan di Indonesia sangat mengkhawatirkan, dengan pertumbuhan jumlah kendaraan yang terus bertambah setiap tahunnya dan tingkat mobilitas penggunanya yang tinggi memiliki kemungkinan untuk terjadinya kecelakaan lalu lintas sangatlah tinggi. Sistem peringatan antar kendaraan dikembangkan dengan tujuan untuk meningkatkan keselamatan dijalan, termasuk juga untuk memberikan kenyamanan pengendara dan penumpang ketika berkendara. Sistem ini terdiri dari sistem komunikasi antar kendaraan menggunakan wireless IEEE 802.11 y yang terintegrasi dengan perangkat embedded system serta dibekali program mengirim dan menerima pesan. Sistem ini akan dipasang pada setiap kendaraan yang bertindak sebagai pengirim informasi/pesan penting seperti informasi keadaan darurat. Pada sisi kendaraan penerima akan ditambahkan perangkat LCD untuk menampilkan informasi serta speaker untuk memberikan bunyi tanda peringatan bahaya kepada pengemudi kendaraan. Hasil yang diperoleh pada penelitian ini adalah prototype sistem peringatan antar kendaraan yang memungkinkan setiap kendaraan dalam range tertentu dapat saling bertukar informasi. Informasi yang dikirimkan antar kendaraan dapat berupa pesan peringatan antar kendaraan ketika terjadi keadaan darurat dijalan.
\end{abstract}

Keywords: Intellegent Transportation System, Vehicular Ad Hoc Network, Sistem Peringatan

\section{PENDAHULUAN}

Kecelakaan lalu lintas dapat terjadi dimana saja dan kapan saja serta berlangsung sangat cepat tanpa diduga terlebih dahulu. Meskipun demikian, kecelakaan lalu lintas sering terjadi pada suatu ruang dan waktu tertentu dan cenderung merupakan keberulangan dengan tipe kecelakaan yang hampir sama sehingga memunculkan adanya dominasi dari suatu tipe kecelakaan tertentu, maka hal ini mengindikasikan adanya suatu faktor penyebab tertentu yang cenderung mempengaruhi kecelakaan tersebut. Pada dasarnya kecelakaan melibatkan banyak faktor, akan tetapi terdapat tiga faktor utama yang menjadi penyebab kecelakaan secara umum [1], yaitu: faktor manusia (pengemudi dan pejalan kaki), faktor jalan dan lingkungannya serta faktor kendaraan.

Dari ketiga faktor tersebut, faktor manusia merupakan faktor utama yang mendominasi terjadinya kecelakaan lalu lintas, tetapi faktor jalan dan lingkungannya beserta faktor kendaraan tetap tidak dapat dipandang sebelah mata sebagai faktor yang berkontribusi terhadap kecelakaan. Oleh karena itu, dalam peningkatan keselamatan jalan secara umum diperlukan usaha baik untuk mengurangi maupun mencegah terjadinya kecelakaan lalu lintas yang dapat merugikan baik korban jiwa maupun materi baik melalui usaha mendidik pengguna jalan yang memiliki wawasan keselamatan, menciptakan jalan dan lingkungannya yang berkeselamatan, dan kendaraan yang memiliki tingkat keselamatan yang tinggi.

Untuk mengurangi jumlah kecelakaan di jalan dan meningkatkan keselamatan di jalan raya, kendaraan harus mampu memantau apa yang terjadi di sekitar mereka, meramalkan apa yang akan terjadi selanjutnya, serta melakukan reaksi pencegahan yang sesuai. Hal ini mensyaratkan bahwa setiap kendaraan memiliki sistem komunikasi baik antara kendaraan untuk berkomunikasi satu sama lain maupun perangkat pendukung dijalan. 
Komunikasi antar kendaraan utamanya digunakan untuk pertukaran informasi keadaan berupa lokasi, kecepatan dan akselerasi. Adanya informasi ini, mampu memperingatkan pengemudi agar tidak terjadi kecelakaan yang disebabkan pengemudi tidak melihat keberadaan kendaraan lain saat berada di persimpangan atau kendaraan yang berada di belakang, namun tidak terlihat dari kaca spion. Teknologi ini menawarkan harapan meningkatnya tingkat keselamatan dan efisiensi dalam berkendara.

Sejumlah penelitian terkait sistem peringatan antar kendaraan yang telah dikembangkan sebelumnya diantaranya oleh Nanok Adi Saputra dkk, yang melakukan pengembangan aplikasi vehicular ad-hoc network untuk monitoring kecelakaan mobil dijalan raya. Penelitian ini menggunakan wireless 802.15 (zigbee) dalam membangun sistem komunikasi antar kendaraan. Dari hasil penelitian tersebut delay waktu yang didapatkan masih sangat tinggi sehingga tidak bisa diaplikasikan pada sistem pencegah kecelakaan dijalan raya [2]. Buchenscheit dkk, merancang prototype sistem peringatan dini yang menyebarkan pesan peringatan melalui komunikasi nirkabel untuk memberikan layanan yang lebih baik dan lebih cepat kepada pasien. Implementasi dan pengujian prototip pada notebook konvensional [3]. Adapun pengembangan sistem komunikasi antar kendaraan di Indonesia selama ini masih sebatas kajian [4,5,6] dan terkendala infrastrtuktur serta terbentur persoalan penyediaan teknologi.

$\begin{array}{ccr}\text { Meski } & \text { penelitian } & \begin{array}{r}\text { tentang } \\ \text { sistem }\end{array} \\ \text { peringatan }\end{array}$
kendaraan telah dilakukan, namun belum ada peneliti yang menerapkan pada platform sistem embedded. Dalam penelitian ini, kami merancang dan menerapkan sistem peringatan kendaraan di komputer mikro Raspberry Pi 3. Adapun penyebaran pesan darurat antar kendaraan dijalan memanfaatkan perangkat komunikasi wireless 802.11n yang telah terintegrasi pada Raspberry Pi 3 sebagai media komunikasi antar kendaraan.

Sistem peringatan ini dapat digunakan untuk berbagi informasi antar kendaraan sehingga dapat membantu pengemudi dalam memberikan informasi lebih awal kepada pengendara lain akan kondisikondisi yang berpotensi terjadinya kecelakaan sehingga pengemudi dapat dapat melakukan tindakan antisipasi. Selain itu sistem ini dapat juga digunakan untuk sebagai sistem peringatan antar kendaraan untuk menginformasikan keadaan-keadaan darurat dijalan, dengan begitu pengendara dapat memantau keberadaan kendaraan lain disekitarnya.

\section{TINJAUAN PUSTAKA}

\section{A. Intellegent Transportation System (ITS)}

ITS adalah sistem yang menerapkan teknologi informasi dan komunikasi secara elektronika melalui software dan hardware komputer dalam bidang transportasi jalan, yang mengintegrasikan unsur-unsur lalu lintas seperti infrastruktur transportasi, kendaraan, dan pengguna jalan.

Tujuan sistem ITS adalah membantu sistem transportasi secara keseluruhan agar bekerja secara efektif dan efisien, sehingga dapat mengurangi kepadatan lalu lintas, mengurangi waktu perjalanan, meningkatkan keselamatan, dan pada akhirnya berdampak pada peningkatan produktivitas ekonomi. Secara khusus, munculnya teknologi ini diharapkan dapat mengurangi kemacetan lalu lintas dan jumlah kecelakaan yang dapat menyelamatkan ribuan nyawa di jalan raya.

Teknologi ITS dapat dijadikan sebagai sebuah metode lanjutan dari sistem transportasi yang dibangun dengan mengintegrasikan manusia, kendaraan dan lingkungan dalam suatu sistem informasi dan komunikasi yang terpadu. Teknologi ini diharapkan mampu membangun suatu sistem infrastruktur transportasi yang 
nyaman dengan prioritas utamanya adalah peningkatan keselamatan di jalan (roadsafety). Kelebihan sistem ini mempunyai tujuan dasar untuk membuat sistem transportasi yang mempunyai kecerdasan, sehingga dapat membantu pemakai transportasi dan pengguna transportasi.

Dalam penerapannya, sistem-sistem dalam ITS memerlukan fungsi-fungsi pendukung, fungsi pendukung tersebut meliputi; pengawasan, komunikasi, pemrosesan data, strategi kontrol, panduan navigasi, dan informasi kepada pengguna jalan. Untuk melaksanakan fungsi-fungsi ini, maka diperlukan alat-alat pendeteksi yang berfungsi sebagai pengumpul data dalam jumlah yang besar. Data ini dapat berupa data lalu lintas seperti kecepatan, volume, kepadatan, waktu perjalanan, panjang antrian, masalah kondisi dan geometri jalan, dan lingkungan seperti kabut, banjir di permukaan jalan, atau bencana alam seperti longsor.

\section{B. Vehicular Ad Hoc Network (VANET)}

VANET adalah sebuah bentuk baru dalam komunikasi data untuk kendaraan yang bergerak dengan kecepatan tinggi dan pertukaran informasi terjadi di jalan raya. VANET merupakan kategori dari Mobile Ad-hoc Network (MANET) di mana node tediri dari kendaraan dan Roadside Unit (RSU). Berbasiskan teknologi jaringan nirkabel, VANET telah menjadi sebuah infrastruktur komunikasi penting guna mendukung pengembangan teknologi Intelligent Transportation Systems (ITS). Oleh karena itu, VANET merupakan bagian yang tidak bisa dipisahkan dari ITS.

Sebagai bagian dari pengembangan teknologi ITS, VANET merupakan teknologi yang tergolong baru. Meskipun kehadiran teknologi ini memunculkan sejumlah pengharapan untuk sistem transportasi yang lebih baik, namun penerapannya masih memerlukan kajian yang lebih mendalam dan lebih intensif. Teknologi ini masih berkembang sebagai sebuah paradigma dan telah menarik banyak minat dunia secara luas mulai dari peneliti, profesional dibidang transportasi, industri otomotif, hingga ke pemerintah.

VANET menggunakan Dedicated Short Range Communication (DSRC) untuk peningkatan keselamatan mengemudi dan kenyamanan pengendara. Jaringan VANET memadukan kemampuan komunikasi antar kendaraan (vehicle to vehicle) dan komunikasi antar kendaraan dengan infrastruktur sepanjang jalan (road infrastructur to vehicle). Setiap kendaraan dapat bergabung ke jaringan VANET melalui komunikasi nirkabel antar kendaraan (vehicle to vehicle) atau ke infrastruktur (vehicle to infrastructure). Sehingga memungkinkan kendaraan dalam jarak 100 sampai 300 meter dapat saling terhubung satu sama lain dan pada gilirannya, membentuk sebuah jaringan dengan cakupan yang luas. Gambar 1 menunjukkan struktur jaringan VANET.

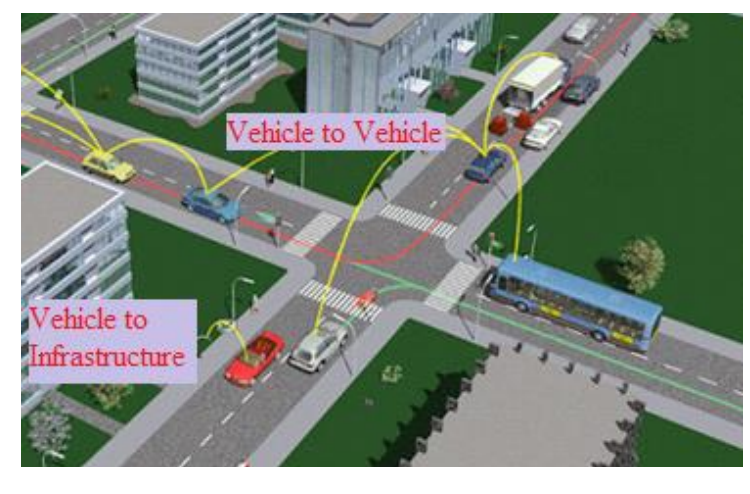

Gambar 1. Struktur jaringan VANET [7]

Berbasis komunikasi jarak pendek dan menengah, jaringan antar kendaraan memungkinkan aplikasi keselamatan bagi kendaraan, termasuk peringatan tabrakan atau keselamatan lainnya.

\section{METODE PENELITIAN}

Penelitian ini dikembangkan dengan memanfaatkan perangkat dan aplikasi teknologi informasi dan komunikasi. Layanan penyebaran pesan peringatan di jalan digunakan untuk menginformasikan hal-hal penting yang sifatnya mendesak agar dapat membantu kelancaran perjalanan pengguna jalan dan 
meningkatkan keselamatan, seperti diperlihatkan pada Gambar 2.

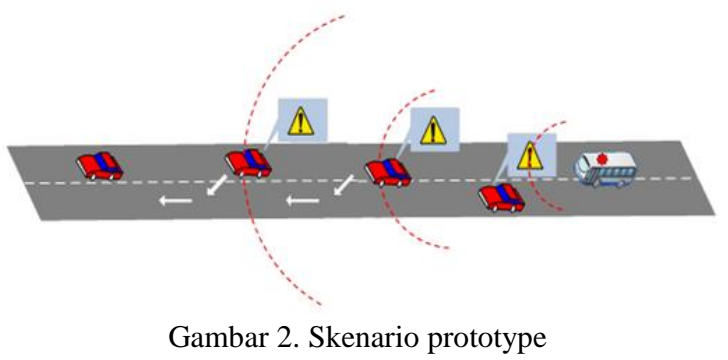

Gambar 3 merupakan diagram use case yang merepresentasikan user requirement dari sistem tanda peringatan di jalan.
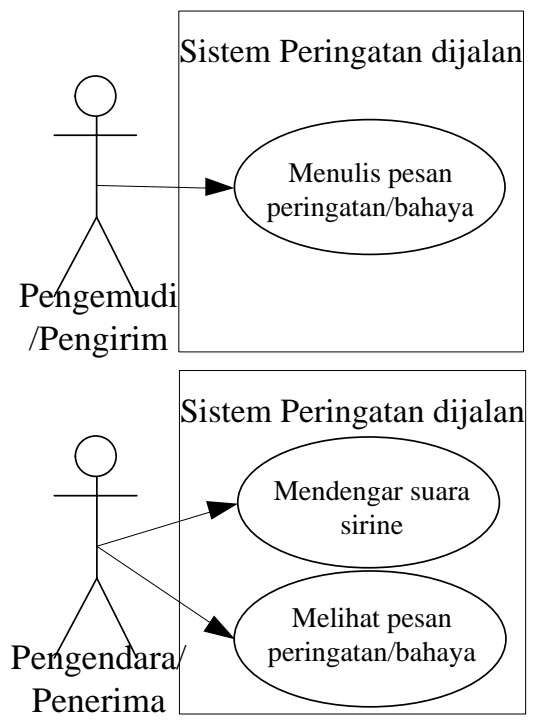

Gambar 3. Diagram use case

Sistem peringatan di jalan ini dibuat sebagai solusi untuk kendaraan darurat yang selama ini masih menggunakan sirine dalam memberikan tanda peringatan bagi kendaraan dijalan. Sistem ini dilakukan secara otomatis dan dijalankan dengan media komunikasi nirkabel. Sistem ini menggunakan komputer mini Raspberry Pi 3 sebagai embedded sistem. Untuk perangkat komunikasinya menggunakan wireless IEEE 802.11n. Dalam komunikasinya hanya dapat dilakukan satu arah, yaitu dari perangkat transmitter yang dipasang pada kendaraan darurat sebagai pengirim pesan ke receiver yang dipasang pada kendaraan umum/pribadi yang bertindak sebagai penerima pesan.

Perancangan dan realisasi perangkat sistem komunikasi antar kendaraan, secara umum terdapat dua bagian utama yaitu bagian pemancar dan penerima. Adapun blok diagram perancangan hardware sistem secara keseluruhan ditunjukkan pada Gambar 4.

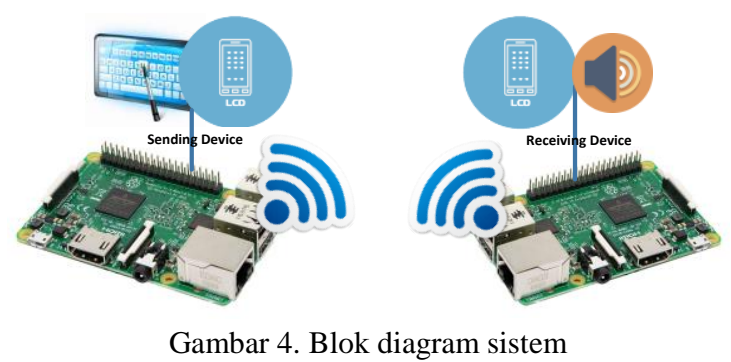

- Bagian Pemancar

Bagian pemancar berfungsi mengirimkan pesan/informasi peringatan ketika terjadi kondisi darurat dari mobil ambulan, polisi atau pemadam kebakaran kepada kendaraan lain dijalan, atau dapat juga digunakan untuk memberikan informasi adanya insiden dijalan agar pengendara dapat melakukan antisipasi.

Untuk bagian pemancar terdapat mini komputer Raspberry Pi 3 yang dilengkapi dengan koneksi wireless berteknologi IEEE 802.11n yang telah diinstall Raspbian Linux serta dibekali interface LCD untuk menjalankan aplikasi pengiriman pesan darurat. Perangkat pemancar ini dipasang pada kendaraan layanan darurat seperti mobil ambulan, polisi atau pemadam kebakaran. Adapun tampilan alat pengirim pesan darurat seperti ditunjukkan pada Gambar 5.

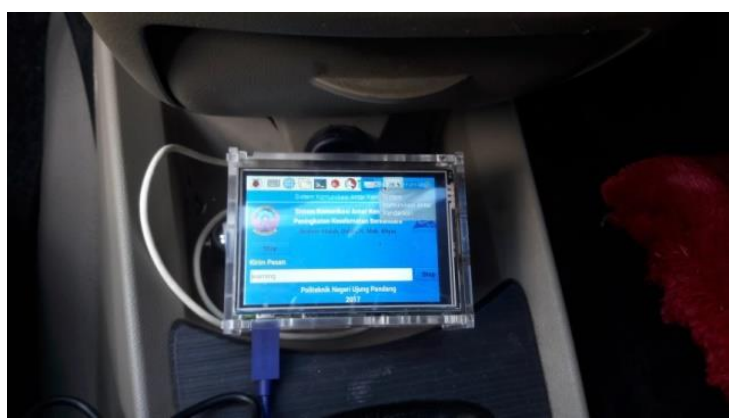

Gambar 5. Tampilan alat pengirim pesan darurat

- Bagian Penerima

Bagian penerima adalah bagian yang berfungsi menerima pesan/informasi dari 
pemancar. Seperti pada pemancar, bagian ini juga terdiri dari embedded system berupa mini komputer Raspberry Pi 3 yang telah dibekali dengan prosesor pendukung Broadcom BCM2837 ARMv8A Quad Core 64 bit dan dukungan Wireless IEEE 802.11 n.

Pada Raspberry Pi 3 ditambahkan bagian antar muka berupa speaker dan LCD, yang fungsinya untuk memberikan tanda berupa bunyi kepada pengemudi ketika mendapat pesan/informasi dari pemancar dan kemudian menampilkan informasi tersebut ke LCD. Perangkat ini ditempatkan dikendaraan umum/pribadi untuk membantu pengemudi menerima pesan yang dikirimkan oleh kendaraan layanan darurat dijalan. Adapun tampilan alat pengirim pesan darurat seperti ditunjukkan pada Gambar 6.

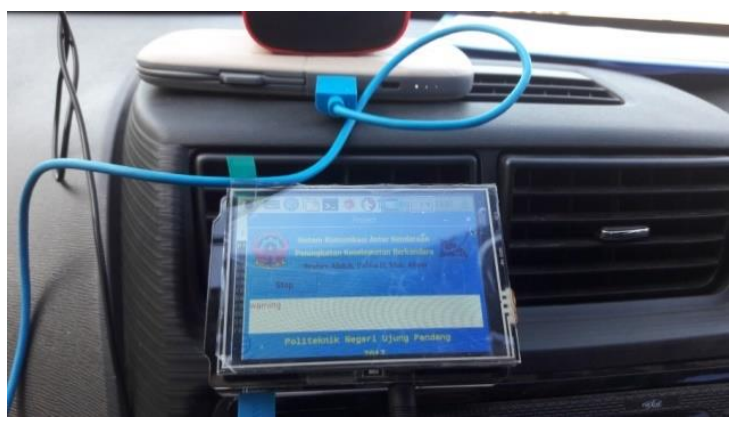

Gambar 6. Tampilan alat penerima pesan darurat

Dalam perancangan software, perangkat ini menggunakan sistem operasi Raspbian Linux yang telah dinstall beberapa software pendukung untuk mengaktifkan perangkat antarmuka dan membangun koneksi jaringan wireless adhoc. Pembuatan aplikasi pengirim dan penerima pesan menggunakan program Gambas. Pada sisi pengirim, pengguna disediakan kolom pengisian teks sebagai pesan darurat yang akan dibroadcast ke semua pengendara dijalan melalui sistem komunikasi wireless. Adapun aplikasi pada sisi penerima akan menampilkan pesan teks tersebut ke LCD.

Untuk mengatasi keterbatasan jarak jangkauan dari sumber pengirim pesan, maka proses penyebaran pesan darurat menggunakan mekanisme multi hop, yakni pesan darurat dikirim secara broadcast ke kendaraan tetangga yang kemudian pesan tersebut akan diteruskan lagi ke kendaraan yang lain yang berdekatan sampai batas yang telah ditentukan. Skenario multi hop dapat dilihat pada Gambar 7.

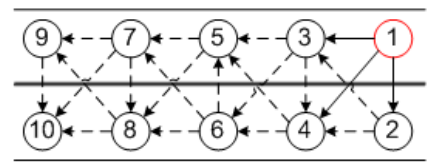

Gambar 7. Mekanisme pengiriman pesan dengan mekanisme multi hop

Proses pengiriman multi hop dibuat menggunakan program socket $\mathrm{C}$, yang berfungsi meneruskan kembali pesan packet UDP yang berisi pesan/informasi yang diterima sebelumnya ke jaringan yang ada. Adapun program relay paket dibuat menggunakan bahasa pemrograman $\mathrm{C}$ untuk mengaktifkan socket programming dalam meneruskan pesan/informasi yang diterima.

\section{HASIL DAN PEMBAHASAN}

Pengujian pada sistem komunikasi antar kendaraan untuk mengetahui tingkat keberhasilan pengiriman pesan pada sisi penerima. Skenario pengujian ini bertujuan untuk mengetahui apakah prototype ini mampu digunakan dalam keadaan real dijalan. Skenario dalam pengujian ini adalah kendaraan yang membawa alat penerima pesan berada didepan kendaraan pengirim, serta berjarak $>50$ meter dari pengirim. Pengambilan data dilakukan dengan variasi kecepatan pengirim dari 10 $\mathrm{km} / \mathrm{jam}-100 \mathrm{~km} / \mathrm{jam}$. Hasil pengujian ini hanya berupa data keberhasilan atau tidaknya receiver menerima data dari transmitter, pada kondisi kecepatan transmitter ketika mengirim data. Hasil pengambilan data dari pengujian dapat dilihat pada Tabel 1.

Dari data hasil pengujian, dapat dilihat dengan kecepatan maksimal pengujian yaitu $90 \mathrm{~km} / \mathrm{jam}$, data dari transmitter masih dapat diterima oleh receiver dengan jarak diatas 50 meter. 
Tabel 1. Pengujian status pengiriman pesan antar kendaraan

\begin{tabular}{|c|c|c|c|}
\hline No & $\begin{array}{c}\text { Kecepatan } \\
\text { pengirim }\end{array}$ & $\begin{array}{c}\text { Jarak } \\
\text { (meter) }\end{array}$ & $\begin{array}{c}\text { Status } \\
\text { Pengiriman }\end{array}$ \\
\hline 1 & $\pm 10 \mathrm{~km} / \mathrm{jam}$ & $>50$ & $\begin{array}{c}\text { Pesan } \\
\text { Terkirim }\end{array}$ \\
\hline 2 & $\pm 20 \mathrm{~km} / \mathrm{jam}$ & $>50$ & $\begin{array}{c}\text { Pesan } \\
\text { Terkirim }\end{array}$ \\
\hline 3 & $\pm 30 \mathrm{~km} / \mathrm{jam}$ & $>50$ & $\begin{array}{c}\text { Pesan } \\
\text { Terkirim }\end{array}$ \\
\hline 4 & $\pm 40 \mathrm{~km} / \mathrm{jam}$ & $>50$ & $\begin{array}{c}\text { Pesan } \\
\text { Terkirim }\end{array}$ \\
\hline 5 & $\pm 50 \mathrm{~km} / \mathrm{jam}$ & $>50$ & $\begin{array}{c}\text { Pesan } \\
\text { Terkirim }\end{array}$ \\
\hline 6 & $\pm 60 \mathrm{~km} / \mathrm{jam}$ & $>50$ & $\begin{array}{c}\text { Pesan } \\
\text { Terkirim }\end{array}$ \\
\hline 7 & $\pm 70 \mathrm{~km} / \mathrm{jam}$ & $>50$ & $\begin{array}{c}\text { Pesan } \\
\text { Terkirim }\end{array}$ \\
\hline 8 & $\pm 80 \mathrm{~km} / \mathrm{jam}$ & $>50$ & $\begin{array}{c}\text { Pesan } \\
\text { Terkirim }\end{array}$ \\
\hline 9 & $\pm 90 \mathrm{~km} / \mathrm{jam}$ & $>50$ & $\begin{array}{c}\text { Pesan } \\
\text { Terkirim }\end{array}$ \\
\hline 10 & $\pm 100 \mathrm{~km} / \mathrm{jam}$ & $>50$ & $\begin{array}{c}\text { Pesan Tidak } \\
\text { Terkirim }\end{array}$ \\
\hline
\end{tabular}

\section{KESIMPULAN}

Penelitian ini merancang prototype sistem peringatan antar kendaraan yang berfungsi sebagai aplikasi keselamatan berkendara. Sistem ini akan sangat membantu untuk mengingatkan pengemudi akan kondisi jalan yang berbahaya dan mendukung layanan kendaraan darurat seperti mobil ambulans, polisi dan pemadam kebakaran untuk menyiarkan tanda peringatan ke semua pengendara dijalan. Hasil percobaan sistem peringatan kendaraan ini dapat mengirimkan pesan peringatan dengan kecepatan maksimum kendaraan 90 $\mathrm{km} / \mathrm{jam}$.

\section{UCAPAN TERIMA KASIH}

Ucapan terima kasih ditujukan kepada Kementrian Riset, Teknologi dan Perguruan Tinggi yang telah membiayai penelitian ini.

\section{REFERENSI}

[1] Tamin, Ofyar Z, "Perencanaan dan Pemodelan Transportasi", ITB, Bandung, 2000

[2] Nanok A. S, M. Zen S. H, Taufiqqurahman, Aplikasi Vehicular
Ad-Hoc Network Untuk Monitoring Kecelakaan Mobil Di Jalan Raya. Artikel https://www.pens.ac.id/uploadta/downlo admk.php?id=1770, Diakses 21 Juli 2017.

[3] A. Buchenscheit, F. Schaub, F. Kargl and M. Weber, "A VANET-based emergency vehicle warning system," 2009 IEEE Vehicular Networking Conference (VNC), Tokyo, 2009, pp. 18.

[4] Dia, Hussein, "Introduction of ITS, Proceedings of Short course on Intelligent Transportation Systems", The University of Queensland, Brisbane, Australia, Nov. 2000.

[5] E. Kusnandar, "Intellegent Transportation Systems untuk Indonesia", Kementerian Pekerjaan Umum Badan Penelitian dan Pengembangan Pusat Penelitian dan Pengembangan Jalan dan Jembatan, Volume 1, 2011.

[6] E. Kusnandar, "Intellegent Transportation Systems untuk Jalan Bebas Hambatan", Kementerian Pekerjaan Umum Badan Penelitian dan Pengembangan Pusat Penelitian dan Pengembangan Jalan dan Jembatan, Volume 1, 2011.

[7] Tsugawa, S, "Issues and recent trends in vehicle safety communication systems". IATSS. Research, Journal of international association of traffic and safety sciences, Vol. 29 No.1, 2005 